\title{
Are Generic UX Evaluation Techniques Enough? A study on the UX Evaluation of the Edmodo Learning Management System
}

\author{
Walter T. Nakamura, Leonardo C. Marques, Luis Rivero, Elaine H. T. de \\ Oliveira, Tayana Conte \\ Computer Institute (IComp) - Federal University of Amazonas (UFAM) \\ 69.080-900 - Manaus - AM - Brazil \\ \{walter, lcm, luisrivero, elaine, tayana\}@icomp.ufam.edu.br
}

\begin{abstract}
As technology evolves and new interaction patterns emerge, User eXperience (UX) is becoming more important. Although several UX evaluation techniques have been proposed, there is no enough evidence regarding their adequacy in the e-learning context. This paper presents an analysis of two UX evaluation techniques applied to the Edmodo Learning Management System. We performed a study with 34 students to evaluate the UX of Edmodo and the perceptions of the techniques. Results showed that Edmodo provided a positive $U X$. However, around $41 \%$ of the students reported that they were not able to fully evaluate their UX using the techniques, indicating a need for improvement.
\end{abstract}

\section{Introduction}

The widespread adoption of internet-based technology led educational institutions to the interest in investing in new learning technologies [Zaharias and Pappas 2016]. Powerful platforms, called Learning Management Systems (LMSs), have been adopted to support the teaching and learning processes. As the number of universities which use LMSs grows, researches in terms of principles related to human computer interaction, such as User eXperience (UX), have attracted considerable interest [Harrati et al. 2016].

UX is defined as person's perceptions and responses that result from the use or anticipated use of a product, system or service [ISO 9241-210 2010]. UX considers pragmatic aspects, i.e. traditional usability features that focus on the accomplishment of tasks, and hedonic aspects, i.e. the emotional responses from using a product [Hassenzahl 2003]. It is important that a LMS also provides a positive UX while being usable and facilitating learning. Failure to comply with these quality aspects may result in dissatisfaction, misunderstanding or improper use of these platforms, generating several criticisms and low acceptance [Van Der Linden and Van De Leemput 2015].

Although there are several UX evaluation techniques, there was no evidence of techniques that consider the specifics for evaluating LMSs [Nakamura et al. 2017a]. Researchers have been using generic techniques to evaluate these platforms. Consequently, there is a need for more empirical evaluations of existing UX evaluation techniques. By doing so, it may be possible to verify their suitability for understanding the experiences that are conveyed by LMSs, while allowing adapting them, if necessary.

This paper presents a study conducted with two UX evaluation techniques: User Experience Questionnaire (UEQ) [Laugwitz et al. 2008] and Integrated Experience Acceptance Model (IEAM) [Van Schaik and Ling 2011], chosen after a selection process. 
Our goal is to compare these two techniques and verify their adequacy to evaluate the UX of LMSs. Therefore, we evaluated a LMS called Edmodo ${ }^{1}$. We gathered the participants' perception regarding ease of use, usefulness and intention to use these techniques. Furthermore, the positive aspects, difficulties and suggestions for improvement of these techniques, as well as the difficulties they faced during the accomplishment of the tasks in Edmodo were also gathered. With this work, we intend to provide researchers with information regarding these techniques, while the identified UX problems faced by the students may contribute to the improvement of Edmodo's quality.

The remainder of this paper is organized as follows: Section 2 presents an overview regarding the UX evaluation of LMSs and the techniques used in this study. In Section 3 we describe the processes performed to conduct this study. Section 4 presents the results regarding the difficulties in Edmodo, the UX evaluation process and the UX evaluation techniques. Finally, Section 5 discusses the findings and concludes the paper.

\section{Related Work}

\subsection{UX Evaluation of LMSs}

A positive UX is important for LMSs, playing a vital role in the acceptance, satisfaction and efficiency of educational institutions [Harrati et al. 2016]. Despite its importance, there are few studies regarding the UX evaluation of LMSs [Zaharias and Pappas 2016]. In order to identify which usability and UX evaluation techniques have been applied on LMSs, we performed a systematic mapping [Nakamura et al. 2017a]. The results from our review showed that few studies were conducted regarding the UX evaluation of LMSs. There was also no evidence of specific techniques developed to evaluate the UX of LMSs. As a result, generic techniques have been employed in such context.

Although generic techniques have been used to evaluate the UX of LMSs, there is no evidence of studies conducted to identify whether they can fully capture the experience conveyed by these platforms or not. Regarding usability, for example, LMSs have some specifics (e.g., content relevance and instructional feedback) that are not addressed by generic usability evaluation techniques. Thus, several studies tried to consolidate both interface and pedagogical criteria to evaluate these platforms [Mtebe and Kissaka 2015]. Therefore, there is a need for empirical studies in order to evaluate the adequacy of these UX evaluation techniques in the context of LMSs.

\subsection{UX Evaluation Techniques}

Several techniques have been proposed to evaluate the UX of interactive applications. In this subsection, we describe two of these techniques: UEQ and IEAM, which were chosen after a selection process (detailed in subsection 3.1). These techniques aim to assess the UX of products regarding the Pragmatic Quality (PQ) dimension (goal oriented) and the Hedonic Quality (HQ) dimension (pleasure oriented). The HQ dimension is sub-divided in Hedonic Identification (HQ/I) and Hedonic Stimulation (HQ/S). The HQ/I dimension is related to how user identifies with the product, while the HQ/S is related to how much the product stimulates the user with "novel, interesting or even exciting functionality, content, presentation or interaction style" [Hassenzahl 2003].

\footnotetext{
${ }^{1} \mathrm{http}: / /$ www.edmodo.com/
} 
UEQ is composed by a 7-point semantic differential scale where the users should mark the point that is closest to the adjective that better describes their UX. The technique uses 26 adjectives to evaluate 6 factors: (i) attractiveness, (ii) perspicuity, (iii) efficiency, (iv) dependability, (v) stimulation and (vi) novelty. The PQ dimension is evaluated by perspicuity, efficiency and dependability attributes, while the HQ dimension is evaluated by stimulation and novelty. UEQ also evaluates the Attractiveness (ATT), which is related to the general impression towards a product, evaluated by the attractiveness attribute. The HQ dimension evaluated by UEQ is related only to HQ/S dimension.

IEAM is composed by two parts. The first part evaluates the PQ, HQ/I and HQ/S dimensions, besides the Beauty and Goodness of a product. Each dimension is composed by pairs of adjectives and a 7-point semantic differential scale, similar to the UEQ. The second part is based on the Technology Acceptance Model (TAM) developed by Davis et al. (1989) and is composed by a 7-point Likert scale, aiming to assess participant's level of accordance for each affirmative regarding: (i) Perceived Enjoyment (PE), (ii) Perceived Ease Of Use (PEOU) and (iii) Perceived Usefulness (PU).

Both techniques were translated to Brazilian Portuguese and reviewed by two researchers. The Cronbach Alpha indicated high internal consistency values for both translated techniques, with $\alpha>0.7$.

\section{Study}

As mentioned before, this study aims to compare two generic UX evaluation techniques and verify their adequacy to evaluate LMSs. Our main motivation is that few studies were conducted to evaluate the UX of LMSs. Furthermore, although LMSs have their specifics, there was no evidence of studies regarding the adequacy of generic techniques to evaluate the UX of these platforms. Therefore, there is a need for empirical studies to verify whether these generic techniques can fully capture the UX conveyed by LMSs or not. The next subsections detail the processes employed to conduct the study.

\subsection{Techniques Selection Process}

In Nakamura et al. (2017a), we conducted a systematic mapping to identify the usability and UX evaluation techniques that have been applied to evaluate LMSs. Since specific techniques for UX evaluation of LMSs were not returned, we performed a research to identify the techniques available from other contexts. To do so, we used the work of Rivero and Conte (2017) as a starting point. It contains a list of 227 publications returned from a systematic mapping conducted to identify methods, techniques and tools that have been proposed to evaluate the UX of software applications.

We formulated five Exclusion Criteria (EC) according to the purposes of our study. Considering the large number of participants and the restricted time to conduct the evaluation, we did not consider techniques that need a moderator or some type of monitoring tool (EC1). Since the focus of our study is the student's perceptions regarding the UX of a functional LMS, we did not consider techniques which data are not obtained by the users (EC2) and not evaluates functional prototypes or final applications (EC4). Techniques that are not available for download/consultation (EC5) or are specific to other contexts, e.g. medical, journalism, etc. (EC3) were also not considered.

From a starting set of 227 publications, 170 were excluded based on the exclusion criteria, resulting in 57 accepted publications and a total of 50 unique techniques 
identified. These techniques were analyzed and assessed regarding aspects such as feasibility and availability. Regarding feasibility, for example, some techniques were not applicable to our study, since they were specific to evaluate educational games or needed specific equipment to perform the evaluation. Regarding availability, some techniques did not provide the final applicable questionnaire. At the end of the analysis, two techniques were selected: UEQ and IEAM. The complete classification for each publication can be found in the technical report [Nakamura et al. 2017b].

\subsection{Definition of the Evaluated LMS}

The choice for Edmodo LMS was made due the identification of difficulties by some students while submitting or performing activities through the platform in a class where one of the authors of this paper acted as an administrator of the environment. Furthermore, there was no evidence of studies regarding the evaluation of Edmodo in our review.

\subsection{Participants and Materials}

We carried out the study with 34 students from Federal University of Amazonas (UFAM), enrolled in Human-Computer Interaction class. The following materials were used in this study: (i) an informed consent form, explaining the study and the subjects' voluntariness and confidentiality; (ii) a script with a set of tasks to be performed on Edmodo; (iii) the UX evaluation techniques (UEQ and IEAM); and (iv) the Technology Acceptance Model (TAM) questionnaire proposed by Davis (1989). Such questionnaire (see Table 1) consists of a set of items evaluated by a 7-point Likert scale to obtain a subject's perceptions regarding Perceived Ease Of Use (PEOU), Perceived Usefulness (PU) and Intention to Use (IU). We also added open-ended questions to gather further opinions.

\subsection{Execution}

Two days before the study, we provided a brief introduction about Edmodo to participants and informed them about the study. All participants signed the informed consent form. They were divided in two groups. Considering that the participants may have different backgrounds that may cause undesired effects on the results, we provided a pre-test questionnaire in order to characterize them (principle of balanced design). This questionnaire was composed by questions regarding: (i) prior use of Edmodo, (ii) frequency of use of LMSs and (iii) knowledge level about usability/UX evaluations. We divided the participants in blocks according to their experience. From each block, they were randomly assigned to each group (see Table 2). Each group used only one technique.

A day before the study, participants received, by e-mail, a script with a set of tasks to be performed on Edmodo. Considering that Edmodo is Internet dependent and that the internal network of the institution is instable due to the high number of users, we decided that each participant would carry out the activities in their own home in order to avoid connectivity problems which could interfere on their experience of use. Therefore, we could not record the time spent by the participants during the tasks accomplishment.

The participants performed the following tasks: (i) register on the platform; (ii) join the group of the discipline through provided access code; (iii) change profile photo; (iv) download and read two available content; (v) perform tasks related to each content; (vi) perform an assessment activity. These tasks were chosen since they reflect the main activities performed by learners in Edmodo. Considering that the selected techniques do 
VI Congresso Brasileiro de Informática na Educação (CBIE 2017)

Anais do XXVIII Simpósio Brasileiro de Informática na Educação (SBIE 2017)

not identify the difficulties faced by the participants, the last question in the assessment activity was an open-ended question where participants could describe their difficulties.

Table 1. Evaluated items from TAM questionnaire and additional questions.

\begin{tabular}{|c|c|c|}
\hline & & TAM Questionnaire \\
\hline Dimension & ID & Question \\
\hline \multirow{4}{*}{$\begin{array}{l}\text { Perceived } \\
\text { Usefulness }\end{array}$} & PU1 & $\begin{array}{l}\text { Using the technique improves my performance when } \\
\text { evaluating the experience of Edmodo. }\end{array}$ \\
\hline & PU2 & $\begin{array}{l}\text { Using the technique improves my productivity when } \\
\text { evaluating the experience of Edmodo. }\end{array}$ \\
\hline & PU3 & $\begin{array}{l}\text { Using the technique allows me to fully evaluate the } \\
\text { experience of Edmodo. }\end{array}$ \\
\hline & PU4 & $\begin{array}{l}\text { I find the technique useful for evaluating the experience of } \\
\text { Edmodo. }\end{array}$ \\
\hline \multirow{4}{*}{$\begin{array}{l}\text { Perceived } \\
\text { Ease Of } \\
\text { Use }\end{array}$} & PEOU1 & The technique was clear and easy to understand. \\
\hline & PEOU2 & Using the technique did not require much mental effort. \\
\hline & PEOU3 & I find the technique easy to use. \\
\hline & PEOU4 & $\begin{array}{l}\text { I find it easy to report the experience of Edmodo using the } \\
\text { technique. }\end{array}$ \\
\hline \multirow{3}{*}{$\begin{array}{l}\text { Intention } \\
\text { to Use }\end{array}$} & IU1 & $\begin{array}{l}\text { Assuming that I have access to the technique, I plan to use it } \\
\text { to evaluate the experience of a learning platform. }\end{array}$ \\
\hline & IU2 & $\begin{array}{l}\text { Given that I have access to the technique, I predict that I } \\
\text { would use it to evaluate the experience of a learning platform. }\end{array}$ \\
\hline & IU3 & $\begin{array}{l}\text { I intend to use the technique to evaluate the experience of a } \\
\text { learning platform next month. }\end{array}$ \\
\hline \multirow{2}{*}{\multicolumn{3}{|c|}{$\begin{array}{l}\text { Additional Open-ended Questions } \\
\text { Did you have any pair of adjectives that you did not understand or considered not } \\
\text { applicable in this context? Which ones? }\end{array}$}} \\
\hline & & \\
\hline \multirow{2}{*}{\multicolumn{3}{|c|}{$\begin{array}{l}\text { Did you feel able to fully evaluate your experience with Edmodo using the technique? } \\
\text { What would you change to improve the application of the technique? }\end{array}$}} \\
\hline & & \\
\hline \multicolumn{3}{|c|}{ What was easy when applying the technique? } \\
\hline \multicolumn{3}{|c|}{ What was difficult when applying the technique? } \\
\hline
\end{tabular}

Table 2. Participants division according to the pre-test questionnaire.

\begin{tabular}{|l|l|c|c|}
\hline \multirow{2}{*}{ Question } & \multicolumn{2}{|c|}{ Answers } & \multicolumn{2}{c|}{ Participants } \\
\cline { 3 - 4 } & & $\begin{array}{c}\text { Group 1 } \\
\text { (IEAM) }\end{array}$ & $\begin{array}{c}\text { Group 2 } \\
\text { (UEQ) }\end{array}$ \\
\hline \multirow{2}{*}{$\begin{array}{l}\text { Prior use of } \\
\text { Edmodo }\end{array}$} & Already used & 2 & 3 \\
\cline { 2 - 4 } & Never used & 15 & 14 \\
\hline \multirow{2}{*}{$\begin{array}{l}\text { Experience with } \\
\text { LMSs (frequency } \\
\text { of use) }\end{array}$} & Several times a week & 6 & 7 \\
\cline { 2 - 4 } & Once a week & 2 & 2 \\
\cline { 2 - 4 } & Once a month & 1 & 1 \\
\cline { 2 - 4 } & Never used a LMS & 2 & 2 \\
\hline \multirow{3}{*}{$\begin{array}{l}\text { Knowledge about } \\
\text { usability/UX } \\
\text { evaluation }\end{array}$} & Already performed this type of evaluation \\
\cline { 2 - 4 } & Already learned about it and did some & 2 & 2 \\
\cline { 2 - 4 } & class exercises & 9 & 10 \\
\cline { 2 - 4 } & Already read about it but not in depth & 4 & 3 \\
\hline
\end{tabular}


On the study day, the participants went to a room according to the group they were assigned. Each group evaluated Edmodo using only one technique. The time spent by each participant in the evaluation process was recorded in order to measure the average time necessary to employ the techniques. After the evaluation, the participants received the TAM questionnaire.

\section{Results}

\subsection{Results Regarding Difficulties in Edmodo}

Results from the last question of the assessment activity provided in Edmodo revealed that, within the 34 participants, 15 faced some difficulties during the execution of the tasks on Edmodo. A total of 12 difficulties were reported. The two most reported issues were related to the difficulty in doing a matching task in a quiz and the difficulty in finding the course materials in the group. Both were indicated by 8 out of the 15 participants that reported having difficulties. Regarding the matching task, participants reported that they did not know how to associate the answers, which may indicate that the task is not intuitive enough. They also reported that it does not provide information about how the task can be accomplished. As a result, it may affect the learner's performance when using Edmodo. Furthermore, teachers may not identify whether the students did not answer correctly due to not knowing the answer or not understanding how to perform the task.

Regarding the difficulty in finding the course materials, participants reported that the place where the materials are made available in the group inside Edmodo is not visible enough. Some participants had difficulty to find the materials while others could not even find it. This may impact in the learning process, since participants could try to find similar materials on the Internet and get inappropriate content to answer the questions.

Other 10 difficulties were related to the navigation (e.g. difficulty to go back to the class' page), proper feedback (e.g. identify if the activity was really delivered to the teacher), language (e.g. mix between English and Portuguese), visibility of the items (e.g. difficulty in finding the tasks and where to click in order to accomplish them).

\subsection{Results regarding UX evaluation of Edmodo}

In this section, we will describe the results regarding the UX evaluation of Edmodo. Since the techniques evaluate some different aspects from each other, firstly we will present the results related to commonly evaluated aspects by both techniques: PQ and HQ/S.

Figure 1 shows the results for the dimensions evaluated by: (i) both techniques, (ii) IEAM only, and (iii) UEQ only. Since these dimensions are composed by a set of items in order to capture a single concept (the dimension itself), we calculated the mean score of these items for each evaluated dimension [Sullivan and Artino Jr 2013]. The result is a number ranging from -3 (the most negative result) to 3 (the most positive). Scores smaller than -1 indicate a negative perception of the participants regarding this dimension. Scores between -1 and +1 indicate that the perception was neither positive nor negative. Finally, scores higher than +1 indicate a positive perception of the participants.

Results regarding dimensions evaluated by both techniques indicate that Group 1 showed neutral to $\mathrm{HQ} / \mathrm{S}$, while Group 2 perceived it as positive. These neutral-positive scores may indicate that Edmodo fulfills the participants' needs regarding this dimension. However, there is a room for improvements. For example, more interesting or exciting 
VI Congresso Brasileiro de Informática na Educação (CBIE 2017)

Anais do XXVIII Simpósio Brasileiro de Informática na Educação (SBIE 2017)

resources/functionalities can be developed in order to increase the stimulation provided by the platform. The results for PQ were similar to HQ/S. The Group 1 showed neutral, while Group 2 perceived it as positive. It may indicate that, in general, participants found Edmodo easy to use. Results are in accordance with the open-ended question where, within the 34 participants, 19 (around 56\%) did not face any difficulty with Edmodo. However, 15 participants complained about one or more issues, which may indicate that there are opportunities to improve the platform.

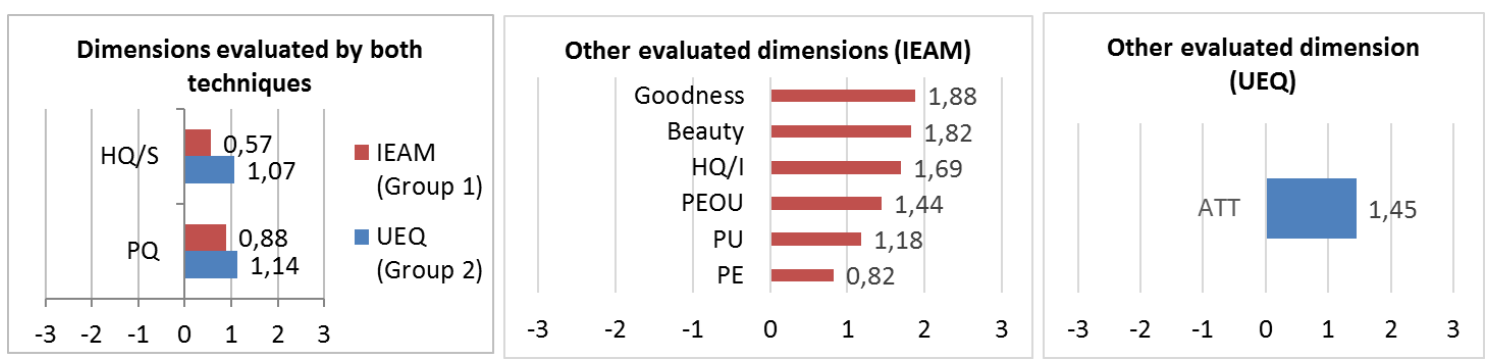

Figure 1. Results from each evaluated dimension of the techniques.

Regarding the remaining dimensions evaluated by IEAM technique (Group 1), results showed that participants did not perceive Edmodo as either enjoyable or unenjoyable $(\mathrm{PE}=0,82)$. On the other hand, they had a positive identification with the platform $(\mathrm{HQ} / \mathrm{I}=1,69)$, found it easy to use $(\mathrm{PEOU}=1,44)$ and useful $(\mathrm{PU}=1,18)$. The platform was also rated as good (Goodness $=1,88)$ and beautiful (Beauty $=1,82)$.

Regarding the other dimension evaluated by UEQ, the Attractiveness (ATT) was perceived as positive $(\mathrm{ATT}=1,45)$. It means that although participants faced some difficulties, the platform was, in general, attractive to them.

In summary, the UX evaluation results showed that Edmodo provides a positive UX to users. However, there is still room for improvements, especially regarding task accomplishment aspects (PQ dimension) and stimulation aspects (HQ/S), in order to make the platform more intuitive and more interesting to learners.

\subsection{Results regarding the evaluation of the techniques}

We applied the TAM questionnaire added with some open-ended questions in order to get participant's perceptions regarding the technique they used. Figure 2 presents the results of TAM questionnaire and the additional open-ended questions.

We calculated the median of each item of TAM questionnaire to compare the two evaluated techniques. Regarding Perceived Usefulness, participants considered that both techniques improve their performance a little when evaluating the UX of Edmodo (PU1). As for productivity (PU2), participants who used IEAM technique considered that it increases their productivity more than participants who used UEQ technique. On the other hand, IEAM technique was perceived as neutral to fully evaluate the experience with Edmodo, while UEQ was perceived as a little useful (PU3). Regarding overall usefulness to evaluate the UX of Edmodo, both techniques were perceived as useful (PU4).

Regarding Perceived Ease Of Use, both techniques were considered clear and easy to understand (PEOU1), with UEQ being perceived as clearer and easier than IEAM. The participants' responses also indicated that both techniques did not require much mental effort (PEOU2) and were very easy to use (PEOU3). These techniques were also perceived as easy to report the experience with Edmodo (PEOU4). 

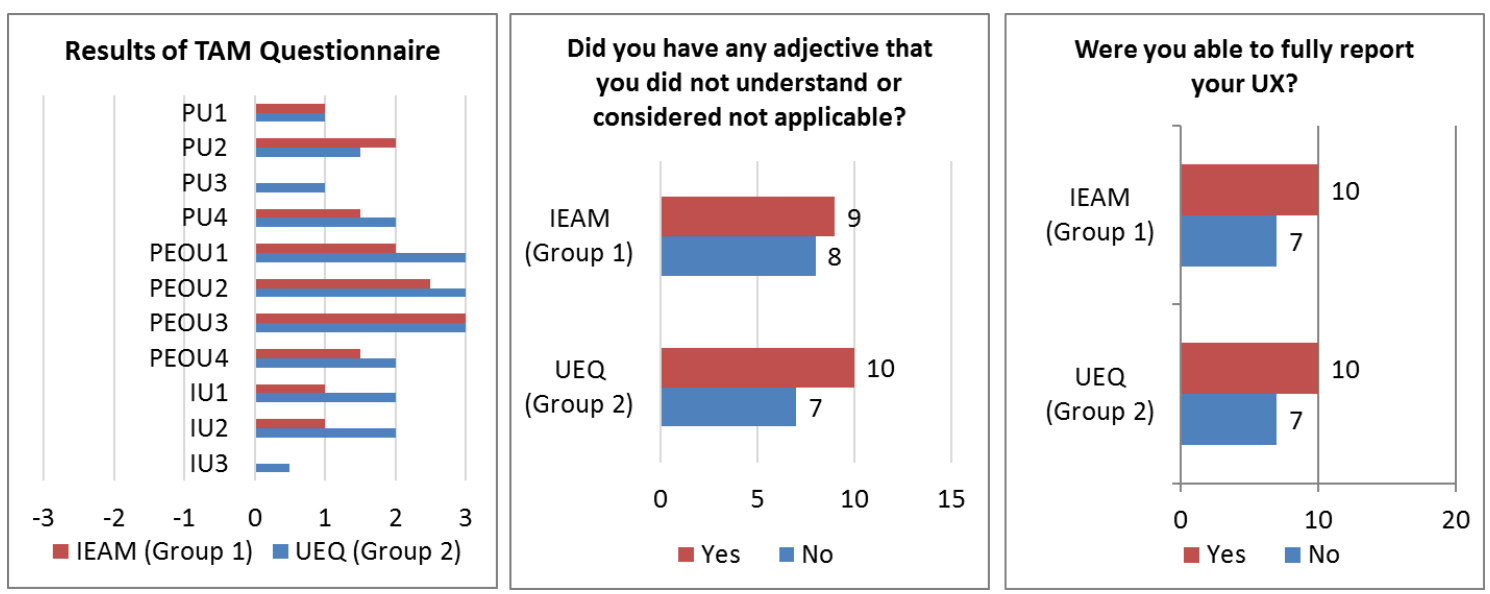

Figure 2. Results of TAM questionnaire and additional open-ended questions.

Regarding Intention to Use, participants who used UEQ showed more intention to use it to evaluate the UX of a LMS than participants who used IEAM (IU1 and IU2). However, participants did not express any intention to use the techniques so soon (IU3).

Regarding the additional questions, when asked whether they found some adjective that they did not understand or considered not suitable to the context, 9 participants from IEAM and 10 participants from UEQ answered yes. Regarding IEAM, most participants complained that the pair "good/bad" is not applicable. Regarding UEQ, most participants complained about the similarity regarding some adjectives, e.g. "inventive-conventional" and "conservative-innovative", while other participants did not understand the meaning of "leading edge" adjective.

Around $41 \%$ of both groups reported that they were not able to fully report their UX using the techniques. Regarding IEAM: 2 participants reported that it is too broad, not specific to evaluate LMSs; 3 participants were not able to describe where they faced difficulties; 1 participant could not give an answer to some questions, marking the neutral option; and 1 participant reported that he/she needed more time to explore the LMS, not being an issue of the technique. Regarding UEQ: 5 participants could not fully report their UX because it did not provide a field to describe their difficulties; 1 participant answered that the evaluation is too broad (not being able to evaluate each functionality individually) and 1 participant reported that using only adjectives is very limited to convey the UX.

When asked what they would change in the technique, regarding IEAM, in general: (i) participants suggested to reduce the scale to 5-point in order to avoid confusion within the terms "agree" and "strongly agree"; (ii) add a field to allow them to describe their difficulties and make comments; (iii) specify which feature is being evaluated by each adjective. Regarding UEQ, in general, participants suggested: (i) removing adjectives that are confusing or not suited for the context; (ii) removing similar adjectives; (iii) add a field for observations and comments.

Regarding the average time needed to employ the techniques, we calculated the mean time spent by the participants in each technique. The results indicated that the UX evaluation can be carried out very quickly through both techniques. However, participants using UEQ performed the evaluation faster (4 minutes) compared to participants using IEAM (7 minutes). It may be due to the second part of IEAM, which require the participants to read the statements in order to answer the questions. 


\section{Discussion and Conclusion}

This paper presented an analysis of two UX evaluation techniques (UEQ and IEAM), chosen after a selection process, in order to evaluate the Edmodo LMS. The results from the UX evaluation of Edmodo showed that even though participants faced some difficulties during the use of the platform, its UX was perceived as positive. However, there is still room for improvements, especially regarding pragmatic aspects. As described before, many students stated that they spent too much time searching for the learning materials. Similarly, many students did not understand how to perform the matching quiz correctly. This can directly impact the learning process, since it increases the cognitive load as students spend more time trying to understand how to use the LMS rather than learning the educational content [Ardito et al. 2006]. Improvements may include positioning the files in locations that are more visible in the group and providing instructions in the matching quiz.

The lowest evaluation received by HQ/S dimension reveals that the platform does not motivate the students very much. Since "motivation and engagement are perhaps the most important elements of every form of learning experience" [Zaharias and Pappas 2016], there is a need to provide more interesting features (e.g. gamification) in order to stimulate the users and make it possible to increase their engagement towards learning.

Regarding the techniques, there was no significant difference regarding their PEOU, PU and IU. However, around $41 \%$ of the participants in both techniques were not able to fully evaluate the UX. Participants reported that the techniques do not provide a field to better express their experiences. They also stated, in both techniques, that some adjectives were not suited to the LMS context, while others were confusing and with similar meaning between them. Additionally, participants reported that the techniques' evaluation were too broad, not specifying which features of the platform are being evaluated. On the other hand, participants perceived the techniques as being easy and fast to perform the evaluation, specially the semantic differential scale.

According to the results, there is a need for techniques that: (i) provide a field where participants can detail their experience, observations or difficulties; (ii) provide questions/adjectives specific to the features of LMSs in order to allow a better evaluation in this context; (iii) specify what the participant is evaluating, since some characteristics may be present in a feature while others not; (iv) provide a quick and easy way to evaluate their UX, such as the semantic differential scales.

We hope that our findings contribute to the improvement of Edmodo and the development and improvement of UX evaluation techniques in the context of LMSs in order to make possible improvements on the quality of these platforms.

\section{Acknowledgements}

We would like to thank the Brazilian funding agency FAPEAM through processes number 062.02646/2014 and number 062.00578/2014.

\section{References}

Ardito, C., Costabile, M. F., De Marsico, M., Lanzilotti, R., Levialdi, S., Roselli, T. and Rossano, V. (2006). An approach to usability evaluation of e-learning applications. In Universal Access in the Information Society Journal, v. 4, n. 3, p. 270-283. 
VI Congresso Brasileiro de Informática na Educação (CBIE 2017)

Anais do XXVIII Simpósio Brasileiro de Informática na Educação (SBIE 2017)

Davis, F. D., Bagozzi, R. P. and Warshaw, P. R. (1989). User acceptance of computer technology: A comparison of two theoretical models. In Management Science, v. 35, n. 8 , p. $982-1003$.

Harrati, N.; Bouchrika, I.; Tari, A. and Ladjailia, A. (2016). Exploring user satisfaction for e-learning systems via usage-based metrics and system usability scale analysis. In Computers in Human Behavior Journal, v. 61, p. 463-471.

Hassenzahl, M. (2003) “The thing and I: Understanding the relationship between user and product", In: Funology: From Usability to Enjoyment, Edited by Blythe, M., Overbeeke, C., Monk, A., Wright, P., Springer Netherlands, p. 31-42.

ISO 9241-210 (2010). Ergonomics of human-system interaction - Part 210: Humancentred design for interactive systems.

Laugwitz, B., Held, T. and Schrepp, M. (2008) "Construction and evaluation of a user experience questionnaire", In: HCI and Usability for Education and Work, Edited by Andreas Holzinger, Springer-Verlag Berlin Heidelberg, p. 63-76.

Mtebe, J. S. and Kissaka, M. M. (2015). Heuristics for evaluating usability of Learning Management Systems in Africa. In IST-Africa 2015 Conference Proceedings, Lilongwe, p. 1-13.

Nakamura, W. T., Oliveira, E. H. T. and Conte, T. (2017a). Usability and User Experience evaluation of Learning Management Systems: A systematic mapping study. In Proceedings of the 19th International Conference on Enterprise Information Systems (ICEIS 2017), v. 3, p. 97-109.

Nakamura, W. T., Marques, L. C., Rivero, L., Oliveira, E. H. T., Conte, T. (2017b) "Support material to the UX Evaluation of Edmodo LMS", TR-USES-2017-0013, USES Research Group Technical Report, http://uses.icomp.ufam.edu.br/relatoriostecnicos.

Rivero, L. and Conte, T. (2017). A systematic mapping study on research contributions on UX evaluation technologies. In Proceedings of the 16th Brazilian Symposium on Human Factors in Computing Systems (IHC 2017), Joinville, Brazil.

Sullivan, G. M. and Artino Jr, A. R. (2013). Analyzing and interpreting data from Likerttype scales. In Journal of Graduate Medical Education, v. 5, n. 4, p. 541-542.

Van Der Linden, J. and Van De Leemput, C. (2015). Observatory of students' uses of computer-based tools. In Psychologie Française Journal, v. 60, p. 145-157.

Van Schaik, P. and Ling, J. (2011). An integrated model of interaction experience for information retrieval in a Web-based encyclopedia. In Interacting with Computers, v. 23, p. 18-32.

Zaharias, P. and Pappas, C. (2016). Quality management of Learning Management Systems: A User Experience perspective. In Current Issues in Emerging eLearning, v. 3 , p. $60-83$. 